\title{
Accommodating Innovation In A Juvenile Court
}

\author{
William H. Barton \\ University of Michigan \\ Jeffrey A. Butts \\ National Center For Juvenile Justice \\ Abstract
}

\begin{abstract}
In an attempt to reduce the number of adjudicated juveniles being committed to the state for placement, the juvenile court in Wayne CountyMichigan implemented three intensive supervision programs to serve as alternatives to commitment. A four-year, randomized evaluation of the programs found them to be cost-effective. An analysis of court processes, however, suggested that the programs gradually came to supplement rather than to displace commitments as intended. The results of this study illustrate how juvenile justice organizations adapt to the presence of alternative programs in ways that dilute their impact.
\end{abstract}

\section{Introduction}

Criminal justice policy makers and researchers often advocate intensive supervision programs as a means of guarding the public safety and enhancing rehabilitative outcomes while avoiding or reducing the costs of incarceration. The appeal of claims made for these programs created a wave of support for intensive supervision programs during recent years (Clear \& Hardyman, 1990). Yet, the success of the programs as alternatives to incarceration is far from clear and may be limited to specific circumstances related to their conceptualization, political support, and implementation (Petersilia, 1990).

In 1983, the Wayne County (Michigan) Juvenile Court initiated three intensive supervision programs as alternatives to state commitment for a substantial number of adjudicated youths. An evaluation study found the programs to be cost-effective (Barton \& Butts, 1990). Yet, as the following analysis demonstrates, the introduction of the alternative programs did not reduce juvenile commitments to the extent intended. The impact of intensive supervision as an alternative was constrained by a number of factors, including accommodations within the juvenile justice system itself. 


\section{The Programs}

Other than transferring a juvenile offender to the adult system, the most restrictive disposition available to Michigan juvenile courts is commitment to the state Department of Social Services (DSS). The majority (80 percent) of juveniles committed to Michigan's DSS are placed in training schools or comparable private institutions.

During the early 1980s, state and local officials were concerned about the number of juvenile commitments originating in Wayne County, a large urban county that includes the city of Detroit. More than 700 youths were committed to DSS from Wayne County in 1982, a higher per capita rate than that of any other Michigan county. In response to this disproportionate utilization, the state adopted an explicit policy goal of reducing Wayne County commitments to 500 per year beginning in 1983 . The county, in turn, implemented three alternative programs to supervise a portion of the youths who otherwise would have been committed. It was hoped that many commitment-bound juveniles could be retained in the community if they were provided with close behavioral supervision and other services.

The three alternative programs differed in their philosophical orientations, but each provided intensive supervision services involving small caseloads and frequent client contact. The Intensive Probation Unit (IPU) was operated by the juvenile court. The Comprehensive Youth Training and Community Involvement Program (CYTCIP) and the home-based services program of Michigan Human Services, Inc. (MHS) were private agencies under contract to the court. ${ }^{1}$ All three programs used a variable mix of individual, group, and family counseling; educational and vocational support; recreation; and behavioral supervision. Each program worker was responsible for about 10 youths. The programs were designed so that each youth would be worked with for one year.

Implementation of the alternative programs included an evaluation to determine cost-effectiveness. For two years, every youth the court recommended for state commitment was screened for eligibility and then randomly assigned to one of the three programs or to a control group. ${ }^{2}$ The juveniles diverted to intensive supervision $(n=326)$ had their commitment recommendations rescinded but remained on probationary status. The youths comprising the control group $(n=185)$ were committed to the state, just as they would have been without the evaluation's random assignment. The evaluation found the randomization process to be successful in dividing the 511 study youths into equivalent groups.

Each case was followed for two years after randomization. Data were obtained by interviewing the youths, their parents, and program staff, as well as examining various court and agency records. The major finding of the Wayne County evaluation was that, in terms of recidivism and other measures, the outcomes of intensive supervision were nearly identical to those of commitment, whereas intensive supervision cost one third as much 
as commitment to the state (see Barton \& Butts (1990) for a complete discussion).

The intensive supervision programs appeared to be cost-effective alternatives to commitment. Yet, their value was diminished by organizational adaptations within the juvenile justice system. The programs initially achieved the goal of reducing commitments to 500 per year, but commitments soon crept back to well over 600 . Why did this happen? Was the court faced with an overall increase in cases, or did it recommend commitment for a higher proportion of cases after the intensive supervision programs became available? Patterns in court processing suggest the latter: when the rate of commitments is analyzed as a function of the volume of petitions filed in the juvenile court, commitments increasingly exceeded expectations. Given an increase in the number of recommended commitments, did the number of youths eligible for diversion increase beyond the new programs' capacity to accept them, thus preventing a reduction in commitments? Or, did the screening criteria change so that the proportion of eligible youths declined? The analysis below demonstrates that both trends occurred as the juvenile justice system adapted to the presence of the programs.

\section{Organizational Context}

The system's inability to maintain a reduction in commitments could have been the result of many factors. It did not appear to be an intentional subversion of policy. More likely, it was the product of organizational forces that combined to thwart the good intentions of the court and the state. Policy makers who initiate alternative programs must contend with social, political, and economic factors that can influence program outcomes. They confront particularly acute pressures from fiscal constraints and their (not necessarily accurate) perception that the public favors a strict law and order approach to juvenile crime (Cullen, Cullen \& Wozniak, 1988; Galvin \& Polk, 1983; Steinhart, 1988). There are also significant organizational incentives for juvenile justice systems to avoid implementing true alternatives (Thomson, 1990; Tonry, 1990).

Organizational behaviors are shaped by resource scarcity, competition with other organizations, cultural values and norms, and the overall political climate. These factors are part of the organization's environment. Seemingly aberrant organizational behaviors may be logical when considered from an environmental perspective. Sociologists such as Selznick (1949) and Gouldner (1954) were among the first to show how organizations survive by adapting to the environment. As organizations grow more complex, they become institutionalized: their activities focus on growth and survival as well as on the attainment of their official goals (Messinger, 1955; Zald \& Denton, 1963). Organizational structures and processes are in some part a manifestation of prior efforts to establish predictability in the environment and to manage dependence on external resources (Aldrich, 1979; Child, 
1972; Emery \& Trist, 1965; Lawrence \& Lorsch, 1967; Pfeffer \& Salancik, 1978; Yuchtman \& Seashore, 1967).

Organizational resources typically include money, staff, clients, authority, and autonomy. To the juvenile justice system in Wayne County, the commitment of juveniles was related to several valued resources. Transferring serious juvenile offenders to state custody (with state-funded supervision and placement) allowed the system to direct its energies and resources to larger numbers of delinquent youths. In fact, the original impetus for the intensive supervision programs was that smaller Michigan counties were perturbed by Wayne County's disproportionate utilization of the finite commitment slots provided by DSS.

The addition of the intensive supervision programs was clearly beneficial to the Wayne County system. The system could benefit even more, however, by implementing the new programs while retaining the original level of commitment resources. Over time, the system managed to achieve this outcome through several internal adaptations. One adaptation was to increase the number of recommended commitments. Another adaptation was to modify various post-commitment factors, such as increasing lengths of stay in the programs and preventing cases from being diverted to the programs by "rehearing" them in court. The following analysis demonstrates how these adaptations effectively restored the rate of Wayne County commitments despite the introduction of the alternative programs.

\section{Increasing Commitment Recommendations}

In order to determine whether commitment recommendations increased in response to the new programs, it is necessary to estimate what the commitment rate would have been in the absence of the in-home programs. The procedure developed for this estimation relies upon the simple assumption that the number of juvenile court commitments should vary directly with the number of petitions filed in the court and with the proportion of serious charges contained in those petitions. Admittedly, this assumption does not account for the complexity of courtroom decisions. However, if the commitment rate is found not to vary predictably with the rate of petitions and serious charges coming before the court, then non-offense factors must be affecting the commitment rate. While not the only explanation, the availability of more programming spaces (the addition of the alternative programs) must be considered one of the more plausible reasons for an increasing rate of commitment recommendations.

The first four rows of Table 1 contain information provided by the Wayne County Juvenile Court for each year between 1981 and 1986, indicating the number of delinquency petitions filed, the proportion of charges for criminal offenses (excluding status offenses, curfew violations, etc.), the number of petitions weighted by the proportion of criminal charges, and the number of commitments. The next two rows show the commitment rate as a propor- 
tion of all petitions and as a proportion of petitions weighted by criminal charges.

\section{Table 1}

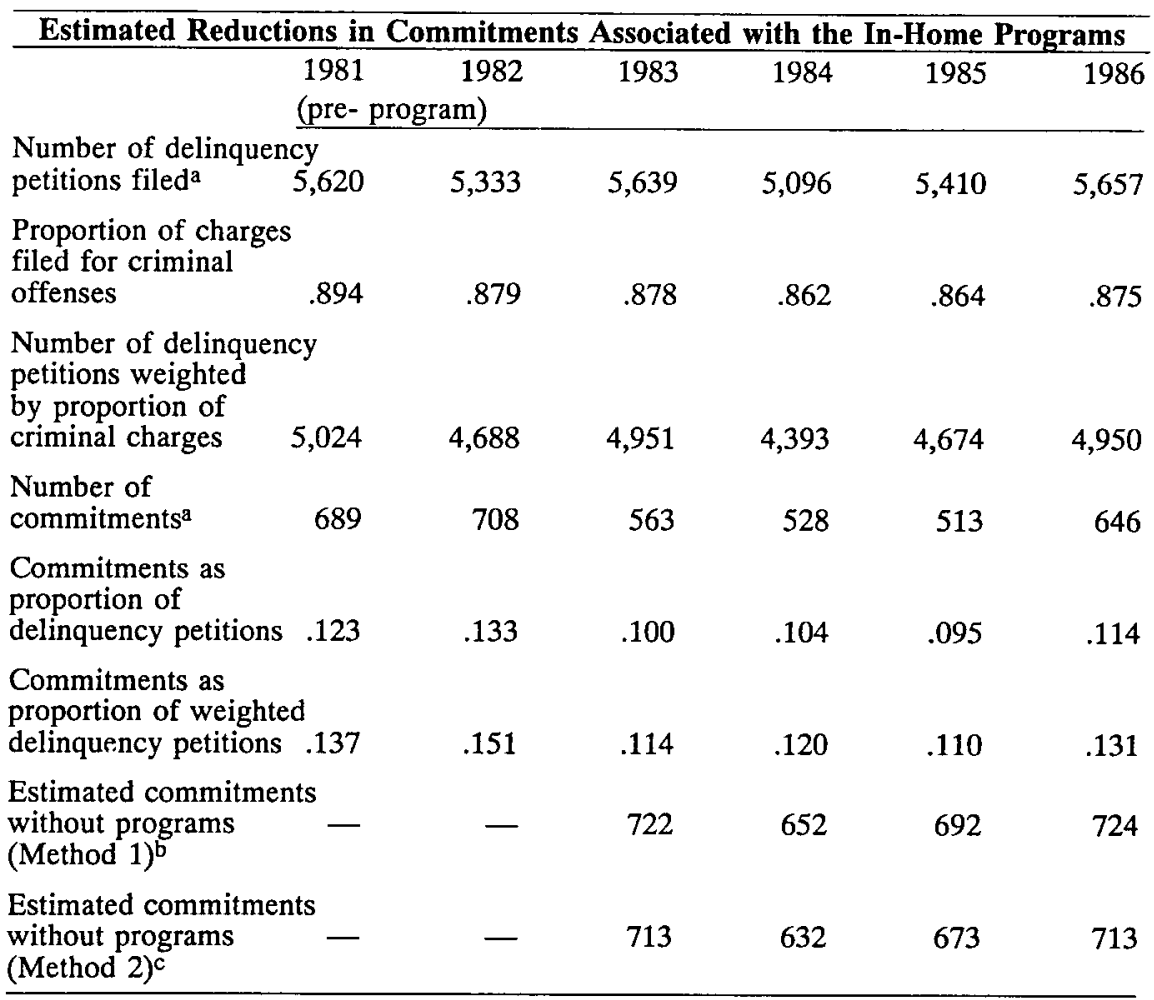

a. Source: Wayne County Juvenile Court, Annual Report 1986.

b. Method 1 estimates commitments as a percentage of all petitions filed. Estimator $=$ .128 , derived from pooled 1981 and 1982 (pre-program) data.

c. Method 2 estimates commitments as a percentage of petitions for criminal offenses only. Estimator $=.144$, derived from pooled 1981 and 1982 (pre-program) data.

The last two rows in Table 1 use the pooled pre-program data from 1981 and 1982 to estimate the number of commitments that would have been made in each subsequent year had the programs not been introduced. For example, the average proportion of all delinquency petitions resulting in commitments in 1981 and 1982 was .128 (the average of .123 for 1981 and .133 for 1982). Applying this pooled estimator to the number of 1983 petitions $(5,639)$ yields an estimated 722 commitments that would have been made in 1983 without the programs. Subsequent estimates projected 652 commitments in 1984, 692 in 1985, and 724 in 1986. Basing the estimate on the number of petitions for criminal charges, on the other hand, yields a slightly different figure. In 
1986, for example, this method projects that there would have been 713 commitments in the absence of the alternative programs. In fact, 646 commitments were made in 1986. Thus, the programs appear to have reduced 1986 commitments by somewhere between 67 and 78 cases, depending upon which estimation method is used (i.e., the difference between 646 and either 713 or 724$)$.

If intensive supervision was used as a true alternative for commitmentbound youths, the number of cases entering the programs should roughly match the estimated reduction in commitments. If the number of youths entering the programs exceeds the estimate, the excess constitutes an increase in the commitment rate. Table 2 shows the extent of this increase for each year following the introduction of the in-home alternatives. The first row shows the number of cases entering the in-home programs each year. The second row contains the estimates of reduced commitments based upon the data in Table 1.

\section{Table 2}

Differences Between the Number of Cases Diverted and Estimated Reductions in Commitments, 1983-1986

\begin{tabular}{lrrrr}
\hline $\begin{array}{l}\text { Number of cases } \\
\text { entering the programs }\end{array}$ & 1983 & 1984 & 1985 & 1986 \\
$\begin{array}{l}\text { Estimated reduction } \\
\text { in commitments }\end{array}$ & $150-159$ & $104-124$ & $160-179$ & $67-78$ \\
$\begin{array}{l}\text { Difference } \\
\text { (Net-widening) }\end{array}$ & $15-24$ & $32-52$ & $40-59$ & $72-83$ \\
\hline
\end{tabular}

a. Includes 166 eligible cases assigned to the programs plus 8 youths referred by judges outside of the screening process. These judicial overrides did not occur in later years of the study.

b. Range of estimated reductions derived in Table 1.

The difference between the number entering the programs and the reduction in commitments is presented in the third row of Table 2. The difference grows each year following the introduction of the programs, from about 20 cases in 1983, to 42 cases in 1984, 50 cases in 1985, and 78 cases in 1986. This steady increase suggests that the juvenile justice system gradually accommodated the presence of the alternative programs by increasing the likelihood of a commitment recommendation prior to screening for program eligibility. Coupled with the changes discussed in the next section, this accommodation appears to have diluted the impact of the intensive supervision programs.

\section{Modifying Post-Commitment Factors}

A higher rate of commitment recommendations cannot account entirely for the resurgence in actual commitments coming from Wayne County. Juvenile court processes that occur after the initial commitment recommen- 
dation (e.g., eligibility screening and program assignment) "feed back" into the system and helped maintain the rate of actual commitments by restricting access to the programs. Together, these processes made intensive supervision available to a decreasing proportion of commitment-bound youths in the years following the inception of the alternative programs.

Table 3 presents summary data regarding program diversions and commitments for the five calendar years following the introduction of the programs. The total number of commitment recommendations increased from around 700 to over 800 per year. Actual commitments ranged from 510 to 535 per year between 1983 and 1985 , closely approaching the County's target level of 500 per year. The rates then jumped to 652 in 1986 and 638 in 1987. Although the three programs increased their combined capacity from 150 youths initially to about 200 in late 1985, the number of cases

Table 3

\begin{tabular}{|c|c|c|c|c|c|}
\hline \multicolumn{6}{|c|}{$\begin{array}{l}\text { Case Flow Summary by Calendar Year, 1983-1987 } \\
\text { Calendar Year }\end{array}$} \\
\hline & 1983 & 1984 & 1985 & 1986 & 1987 \\
\hline Recommended Commitments ${ }^{\mathbf{a}}$ & 701 & 667 & 729 & 802 & 807 \\
\hline Eligibles & $\begin{array}{r}224 \\
32.0 \%\end{array}$ & $\begin{array}{r}286 \\
42.9 \%\end{array}$ & $\begin{array}{r}318 \\
43.6 \%\end{array}$ & $\begin{array}{r}303 \\
37.8 \%\end{array}$ & $\begin{array}{r}240 \\
29.7 \%\end{array}$ \\
\hline Assigned to Programs & $\begin{array}{r}166 \\
23.7 \%\end{array}$ & $\begin{array}{r}184 \\
27.6 \%\end{array}$ & $\begin{array}{r}273 \\
37.4 \%\end{array}$ & $\begin{array}{r}263 \\
32.8 \%\end{array}$ & $\begin{array}{r}240 \\
29.7 \%\end{array}$ \\
\hline Entered Programs & $\begin{array}{r}166 \\
23.7 \%\end{array}$ & $\begin{array}{r}156 \\
23.4 \%\end{array}$ & $\begin{array}{r}219 \\
30.0 \%\end{array}$ & $\begin{array}{r}150 \\
18.7 \%\end{array}$ & $\begin{array}{r}169 \\
20.9 \%\end{array}$ \\
\hline Rehearings ${ }^{b}$ & $\begin{array}{r}0 \\
0.0 \%\end{array}$ & $\begin{array}{r}28 \\
4.2 \%\end{array}$ & $\begin{array}{r}54 \\
7.4 \%\end{array}$ & $\begin{array}{r}113 \\
14.1 \%\end{array}$ & $\begin{array}{r}71 \\
8.8 \%\end{array}$ \\
\hline Misc. Ineligibles $c$ & $\begin{array}{r}4 \\
0.6 \%\end{array}$ & $\begin{array}{r}25 \\
3.7 \%\end{array}$ & $\begin{array}{r}28 \\
3.8 \%\end{array}$ & $\begin{array}{r}110 \\
13.7 \%\end{array}$ & $\begin{array}{r}158 \\
19.6 \%\end{array}$ \\
\hline Parental Refusal ${ }^{\mathbf{d}}$ & $\begin{array}{r}149 \\
21.3 \%\end{array}$ & NA & $\underline{N A}$ & NA & $\begin{array}{r}39 \\
4.8 \%\end{array}$ \\
\hline Actual Commitments & $\begin{array}{r}535 \\
76.3 \%\end{array}$ & $\begin{array}{r}511 \\
76.6 \%\end{array}$ & $\begin{array}{r}510 \\
70.0 \%\end{array}$ & $\begin{array}{r}652 \\
81.3 \%\end{array}$ & $\begin{array}{r}638 \\
79.1 \%\end{array}$ \\
\hline
\end{tabular}

a. To avoid double counting, rehearings are subtracted from the total.

b. Rehearings are requested by parents to prevent an assigned diversion case from actually entering an in-home program.

c. Miscellaneous ineligibles are those excluded for reasons other than failing to meet the explicit eligibility criteria.

d.Parental refusals refer to the pre-assignment exclusion of cases otherwise meeting the eligibility criteria. The court re-introduced this option in 1987.

e. The number of actual commitments in each year is slightly different from that shown in Table 1 which uses data from the court's Annual Report and represents courtroom actions. These data represent decisions made during and subsequent to eligibility screening, which often occurred several days after the courtroom hearing. Thus, a youth recommended for commitment on December 28, 1985 might be counted in the 1986 screening data. 
actually entering the programs was less than 170 in every year except 1985 . The intended reduction in commitments was limited by three additional factors: lengths of stay in the programs, discretionary eligibility exclusions, and "rehearings."

\section{Length Of Stay}

The programs were originally designed to work with youths for about one year. Case turnover quickly became problematic, however, and many youths received more than a year of intensive supervision. In the first two years, this extended retention produced few problems because the demand for program spaces was limited by the assignment of some eligible cases to the control group. Extended program stays may have actually helped the programs maintain adequate caseloads during this time. By 1985, however, demand for the programs exceeded available spaces.

One response might have been a reduction in average length of stay, but this did not occur. During the first year of program assignments, just over 33 percent of the cases entering the programs were retained for longer than twelve months. During the second year, all three programs showed an increase in the number of cases being retained for more than a year, from one-third to nearly half of all cases. In 1985, IPU and CYTCIP reduced the percentage of these cases, but MHS continued to keep more youths (about 53 percent of all their cases) for lengthy stays. Overall, about 44 percent of the 1985 cases and 43 percent of 1986 cases remained active for more than one year.

When one considers that about half of the cases entering the programs failed (i.e., were re-arrested or otherwise terminated before completing the program), and that most of these failures occurred in less than a year, the length-of-stay patterns mean that the programs elected to retain the rest of their cases far longer than the 12-month target. The evaluation estimated that the programs retained between 60 and 70 percent of their successful cases for more than a year. Despite the possible merits of lengthy stays, they restricted access to intensive supervision for other youths coming through the system. As of 1985, the lack of program capacity created a log-jam at the point of program screening, thereby encouraging the use of other adaptive mechanisms.

\section{Rehearings And Discretionary Screening}

During the experimental phase (the first two years of program operation), the eligibility criteria were fairly explicit, excluding cases with no adequate home (active neglect cases), violent offenses, severe psychiatric disturbances, etc. In the first year, parents were given the opportunity to refuse diversion prior to case screening and many did, as seen in Table 3 ( 21 percent of all cases, and up to 40 percent of those who would otherwise have been eligible). About 32 percent of all cases screened in the first year were deemed eligible, although random assignments to the control group meant that not all eligible 
cases were assigned to the programs. Thus, about one-fourth ( 24 percent) of all cases actually entered the programs in 1983. Commitments totaled 535 for the year.

Procedures were altered in the second year, eliminating the pre-screening option of parental refusal. Parents could still refuse to accept the youth's diversion to intensive supervision, however, by filing for a rehearing of the case shortly after notification of the court's intent. Only 28 parents filed for rehearings in 1984. As a result, the eligibility rate increased to 43 percent. Since random assignments to the evaluation's control group continued, the proportion actually entering the programs did not increase markedly. The total number of commitment recommendations fell from 701 to 667 , and the number of actual commitments was similarly reduced to nearly 500 .

As planned, random assignments into the evaluation study ceased early in 1985, and case screening responsibility was transferred from the evaluation staff to court personnel. Since control group assignments had been completed, all eligible cases could be diverted to the programs. The court decided to continue with the same basic eligibility requirements and to distribute eligible cases to the three programs as their capacities permitted. Program capacity had actually increased by then due to an expansion of one of the programs.

The court recommended commitment for 729 cases in 1985, and 44 percent were determined to be eligible for intensive supervision - a percentage almost identical to the proportion deemed eligible in 1984. The number of youths assigned to the programs jumped to 273 , although an increase in rehearings prevented one in five of these youths from actually entering the programs. Still, 219 youths entered the programs in 1985 , constituting 30 percent of all cases. The increased use of intensive supervision held the actual commitment rate to 510 that year, despite the growth in commitment recommendations.

In 1986, several changes combined to increase the rate of actual commitments. Commitment recommendations grew by 73 (to 802), but actual commitments rose by 142 to a total of 652 for the year, nearly matching the pre-program levels of 1981 and 1982. Proportionally fewer cases were deemed eligible in 1986, about 38 percent versus approximately 43 percent in the two previous years. Not all eligible youths were assigned, and there was a large discrepancy between those assigned ( 33 percent) and those actually entering the programs (19 percent). A large increase in rehearings (to 113 cases) prevented over 40 percent of the youths assigned to the programs from entering. Lack of program capacity was cited as the reason an additional 40 eligible youths were not assigned to the programs.

The lack of program capacity and the dramatic increase in rehearings encouraged the court to exercise more discretion in eligibility screenings. One way to reduce diversions and rehearings was to screen out potentially resistant families. The court's case files contained information about the youth's fami- 
ly situation or other factors that might lead one to question their amenability to an alternative, home-based program. Increasingly, youths meeting the original eligibility requirements were declared ineligible for diversion due to "chronic home truancy," "high potential for future delinquency," or "chaotic family environment." Thus, eligibility decisions began to be based on a combination of explicit criteria and clinical judgment. As a result, 110 cases were deemed ineligible for "miscellaneous" reasons in 1986 and the population served by the programs became a still smaller proportion of those ordinarily committed.

With minor modifications, these patterns continued in 1987. The number of commitment recommendations remained high (807), the eligibility rate fell further (to about 30 percent) as miscellaneous exclusions climbed (to 158 , or 20 percent of all cases). The programs were operating below capacity for much of the year, so there was no gap between those eligible and those assigned. ${ }^{3}$ However, rehearings declined to 71 , or 30 percent of those assigned. As a result, the number of youths actually entering the programs rose to 169 , producing a total of 638 actual commitments in 1987. One of the reasons for the reduction in rehearings was the reintroduction of the parental-refusal option prior to program assignment. The reduction in rehearings from 14 percent in 1986 to nine percent in 1987 is nearly accounted for by the five percent parental refusal rate in 1987 .

Figure 1 depicts the combined effect of these dynamics. The top line traces the number of commitment recommendations screened for the programs each year. ${ }^{4}$ The next line plots the actual commitments; the rise in 1986 is apparent. The pattern through 1985 demonstrates the potential of the alternative programs to reduce commitments. By that year, the programs had expanded their capacity, and no more eligible youths were being committed

Figure 1

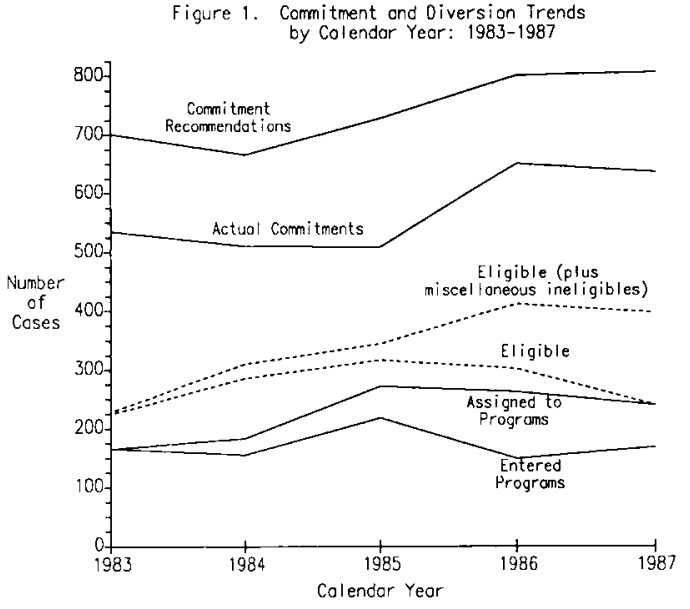


as part of the evaluation's control group. In other words, commitments were being reduced to the maximum extent possible by the use of the alternative programs. In 1986, commitment recommendations increased, but the number of actual commitments rose more dramatically.

The rest of Figure 1 shows how discretionary ineligibility decisions and rehearings contributed to the under-utilization of intensive supervision in 1986 and 1987. The two dashed lines portray the effect of discretionary ineligibility decisions. The upper line shows the number of eligible cases plus the miscellaneous ineligibles and suggests the number who would have been eligible based solely upon the original criteria. The lower dashed line shows only those who were in fact deemed eligible. The widening space between the dashed lines represents the extent to which discretion limited eligibility and helped increase commitments beyond the level that would have followed from the original eligibility criteria. Of course, program capacity would have had to be expanded to serve the approximately 400 youths who could have been eligible in 1986 and 1987.

The bottom two lines depict rehearings-the difference between the number of youths assigned to a program (the upper line) and the number that actually entered one (lower line). The space between these lines expands markedly in 1986 before contracting slightly in 1987. After discretionary ineligibility lowered the pool of potential program clients, rehearings further reduced it to the point that the programs were operating well below capacity.

\section{Discussion}

The intensive supervision programs initially allowed many Wayne County youths who otherwise would have been committed to be supervised at home. In terms of recidivism, the evaluation found the programs to be costeffective. During the first two years of program operation, cases were drawn from the defined target population and their outcomes over a two-year follow-up period were compared with those of the randomly assigned control group. There were no major recidivism differences between the in-home program youths and the control group, either in terms of official charges or self-reported offenses. ${ }^{5}$ During those first two years, the programs enabled the court to reduce the number of commitments as intended.

Unfortunately, later years saw a gradual attenuation of the programs' impact. The programs gradually began to supplement, rather than substitute for commitment. One might argue that an increase in the incidence or seriousness of juvenile crime brought a larger number of serious cases before the court. Perhaps without the programs, the system would have faced the necessity of committing even more youths each year. This explanation has been advanced in other evaluations of alternative correctional programs (Jones, 1990). The information presented above regarding the volume of petitions suggests that such an hypothesis cannot account for all of the observed increase in initial commitment recommendations. The analysis took petition volume 
and the relative proportion of serious cases into account and still found that commitments exceeded expectations.

As commitment recommendations gradually increased, the criteria for diversion changed such that an ever decreasing proportion of otherwise eligible youths actually entered the intensive supervision programs. In principle, there were as many as 400 youths per year who met the original eligibility criteria and who might have been suitable for intensive supervision. Instead of reducing commitments and expanding the programs' capacity to meet this potential, the system acted to limit the pool of commitment cases that could be diverted to the programs. The number of commitments returned to almost pre-program levels while intensive supervision was used for many youths who previously might not have been committed and most likely would have been supervised by regular probation.

The tendency of the justice system to use alternative programs as supplements rather than substitutes is often referred to as net widening (e.g. Austin \& Krisberg, 1981; Cohen, 1985; Decker, 1985; Ezell, 1989; Klein, 1979; Polk, 1987). Intensive supervision programs are often promoted as alternatives to incarceration. As alternatives, they can reap great benefits. However, they must draw their clientele from the offender population likely to be in the net. When they draw instead upon those just outside the netoffenders who would not have been considered for incarceration previouslythe ostensible alternatives do nothing to reduce and may even increase the scope and costs of the justice system. Regardless of whether net widening is seen as expanded social control (Blomberg, 1977), or enhanced delivery of needed services (Binder \& Geis, 1984), it is clearly a failure when the system's professed goal was to reduce its use of incarceration or commitment.

Other jurisdictions seeking to substitute intensive supervision for residential placements could learn from the Wayne County experience. The implementation of alternative programs must be monitored to detect system adaptations and organizational adjustments. The target population for alternative programs should be carefully defined to encompass a portion of youths normally headed for residential placement. Eligibility screening should utilize clear criteria, and program staff should be prepared to terminate successful cases in a tımely fashion in order to permit the entry of new cases. A certain amount of discretion is inevitable, even desirable in cases with extenuating circumstances, but it should be closely controlled.

The above analysis suggests there were organizational incentives for the system to behave as it did. The new programs were a valued resource to the Wayne County juvenile justice system, but maintaining an already established volume of commitments was at least as valuable. The success of community-based programming depends upon the determination of policymakers and administrators to make such programs function as true alternatives to out-of-home placement. To do so, they must resist the organizational 
impulse to augment resources and expand operations by widening the net of intervention.

Notes

1 CYTCIP inherited its program from another agency that was unable to fulfill its initial contract after several months of operation. CYTCIP gradually replaced existing staff and revised the program to its own specifications.

2 Eligibility screening excluded only juveniles charged with a violent offense, those with a history of sever psychiatric disturbance, or those with no potential home in the community. The evaluation was limited to male youths since very few females were committed.

3 In response to this under-utilization of the in-home programs, the court modified some of the explicit eligibility criteria, allowing the diversion of some youths with violent commitment offenses. In practice, however, this modification had little impact as only nine such cases had been diverted as of the end of 1987.

4 Since cases with rehearings appear in court twice and represent an administrative duplication of cases, they are subtracted from the official number of screened commitment recommendations.

5 The program youths were more likely to be charged with status offenses and program violations, but the number of criminal offenses charged against the two groups (controlling for time at large in the community) was not significantly different. There was an incapacitative effect since the control group was incarcerated twice as long on average (13 months) as the program youths. When at large, however, the criminal behavior of the two groups was no different (Barton and Butts, 1990).

Bibliography

Aldrich, $\mathrm{H}$.

1979 Organizations And Environments. Englewood Cliffs, NJ: Prentice-Hall.

Austin, J., and B. Krisberg

1981 Wider, stronger, and different nets: The dialectics of criminal justice reform. Journal Of Research In Crime And Delinquency, 18: $165-196$.

Barton, W.H., and J. A. Butts

1990 Viable options: Intensive supervision programs for juvenile delinquents. Crime And Delinquency, 36: 238-256.

Binder, A., and G. Geis

1984 Ad populum argumentation in criminology: Juvenile diversion as rhetoric. Crime And Delinquency, 30: 624-647. 
Blomberg, T.G.

1977 Diversion and accelerated social control. Journal Of Criminal Law And Criminology, 68: 274-282.

Child, J.

1972 Organizational structure, environment and performance: The role of strategic choice. Sociology, 6: 1-22.

Clear, T.R., and P. L. Hardyman

1990 The new intensive supervision movement. Crime And Delinquency, 36: 42-60.

Cohen, $\mathrm{S}$.

1985 Visions Of Social Control: Crime, Punishment And Classification. Cambridge: Polity Press.

Cullen, F.T., J.B. Cullen, and J.F. Wozniak

1988 Is rehabilitation dead? The myth of the punitive public. Journal Of Criminal Justice, 16: 303-317.

Decker, S.A.

1985 A systemic analysis of diversion: Net widening and beyond. Journal Of Criminal Justice, 13: 207-216.

Emery, F.E., and E. L. Trist

1965 The causal texture of organizational environments. Human Relations, 18: 21-31.

Ezell, $\mathbf{M}$.

1989 Juvenile arbitration: Net widening and other unintended consequences. Journal Of Research In Crime And Delinquency, 26: 358-377.

Galvin, J., and K. Polk

1983 Juvenile justice: Time for new direction? Crime And Delinquency, 29: 325-332.

Gouldner, A.

1954 Patterns Of Industrial Bureaucracy. New York: Free Press.

Jones, P.R.

1990 Community corrections in Kansas: Extending communitybased corrections or widening the net? Journal Of Research In Crime And Delinquency, 27: 79-101.

Klein, M.W

1979 Deinstitutionalization and diversion of juvenile offenders: A litany of impediments. In N. Morris \& M. Tonry Eds., Crime And Justice: An Annual Review Of Research. vol. 1. Chicago: University Of Chicago Press.

Lawrence, P.R., and J. W. Lorsch

1967 Organization And Environment. Cambridge: Harvard University Press. 
Messinger, S.L.

1955 Organizational transformation: A case study of declining social movement. American Sociological Review, 20: 3-10.

Petersilia, J.

1990 Conditions that permit intensive supervision programs to survive. Crime And Delinquency, 36: 126-145.

Pfeffer, J., and G. Salancik

1978 The External Control Of Organizations. New York: Harper \& Row.

Polk, K.

1987 When less means more: An analysis of destructuring in criminal justice. Crime And Delinquency, 33: 358-378.

Selznick, $P$.

1949 TVA And The Grass Roots. Berkeley: University Of California Press.

Steinhart, D.

1988 California opinion poll: Public attitudes on youth crime. NCCD Focus. San Francisco: National Council On Crime And Delinquency.

Thomson, D.R.

1990 How plea bargaining shapes intensive probation supervision policy goals. Crime And Delinquency, 36: 146-161.

Tonry, $\mathrm{M}$.

1990 Stated and latent functions of ISP. Crime And Delinquency, 36: 174-191.

Yuchtman, E., and S. E. Seashore

1967 A system resource approach to organizational effectiveness. American Sociological Review, 32: 891-903.

Zald, M.N., and P. Denton

1963 From evangelism to general service: The transformation of the YMCA. Administrative Science Quarterly, 8: 214-234. 